\title{
AN INDIVIDUAL LEVEL ANAL YSIS OF PSYCHOLOGICAL CAPITAL IN COMBATING OCCUPATIONAL STRESS AT EDUCATIONAL INSTITUTION IN JAIPUR
}

\author{
Mr. Prateek Jain \\ Assistant Professor,School of Business and Management, Jaipur National University, Jaipur (Rajasthan) \\ Dr. Avni Sharma \\ Assistant Professor, School of Business and Management, Jaipur National University, Jaipur (Rajasthan) \\ Prof. Jyotsana Khandelwal \\ Professor, School of Business and Management, Jaipur National University, Jaipur (Rajasthan) \\ Mr. Anmol Gupta \\ Student of BBA, School of Business and Management, Jaipur National University, Jaipur (Rajasthan)
}

\begin{abstract}
In India, a major part of the population does not have access to modern kind of teaching services. The main reason for this financial exclusion in India is the lack of regular or substantial income, excessive documentation for loans \& opening of accounts, lack of proximity of the financial institutions, high transportation cost \& loss of daily wage. Every person has a working life time period of about 35 years, normally between 25 to 65 years of age. In Indian Scenario of competitive market, over population and scarcity of good jobs, run on the theory of 'Survival of the Fittest', No profession is stress free. This has highlighted the fact that how much costs is associated with stress in the workplace and claims for psychological injury are spiraling. As a result, stress and workplace health have become major issues of great concern over the last decade, both internationally and nationally.

The purpose of this study was to synthesize the vast array of literature that exists on the topic of work stress and draw some relevant conclusions regarding to it. The review also aimed to identify areas where further research was necessary and the methodological flaws in existing research that needed to be addressed in this research. To fully understand the phenomenon of work
\end{abstract}

stress, the review first documented the process that most commonly occurs among employees who experienced it. In identifying this process, a plethora of contributory and execratory factors were identified. These factors include individual vulnerabilities, job demands, the organizational climate, the person environment match, the appraisal and perceptions of the worker, human resource management practices, the meditation and legalization of stress. Purpose:-The aim of this study is to analyze the psychological capital of Individual in combating Occupational Stress at educational institutions in Jaipur

Methods: - Data was collected from a sample of Fifty Teachers from different institutions of Jaipur. Following test have been used by the researcher which includes chi Square Test to examine the differences between categorical variables in the same population Conclusion: - Based on the finding of this study, it has been found that stress and workplace health has become issues of great concern over the last decade, both internationally and nationally. Further studies are required to determine the most effective intervention programs for Teachers in Institution 


\section{Key Words: - Psychological Capital, meditation, Self Efficacy}

\section{Introduction}

Stress is defined as an individual perceiving external demands as being beyond his or her ability to cope with these demands. More specifically, stress relates both to individuals' perceptions of the demands being made on them and to their perception of their capability to meet those demands. Major sources of stress includes heavy work load, leadership and management issues, and intraperofessional conflicts, emotional demand of caring, lack of reward, role ambiguity and shift work. It has been demonstrated that occupational stress level among employees in educational institutions in Jaipur is high. Occupational stress experienced by teacher's undesirable personal or organizational outcomes including job dissatisfaction.

\section{Basic components of psychological Capital} Self-efficacy/Confidence Self-efficacy represents the general belief of people while they exhibit their performances and makes a sense beyond the actual abilities that lead to complete tasks. It can be said that high self-efficacy can influence motivation in both positive and negative sides. People who are self-confident know how to improve their motivation. They choose challenging tasks to extend their performance and motivate themselves against the obstacles faced while working for accomplishing goals.

Özkalp said that self-efficacy is not related to the competences on individuals' capabilities, on the contrary it is related to the belief on personal abilities. These people who are self-confident can choose and develop the ways to be able to attain their goals . Self-efficacy can be thought as an inner agent to direct people and effectively execute different tasks and roles in their life. Research by Stajkovic et al. underlined that there is a strong and positive relationship between self-efficacy and performance. Moreover, because of the positive and significant relationship between job satisfaction and performance; it can be easily thought that there is also a positive relationship between self efficacy and job satisfaction.

\section{Hope}

Achieving the desired goals requires the sense of agency and expectations which provide people with an "internalized determination and willpower to invest the energy" [1]. Workers take an example by the leaders in general. Thus, leaders' hope impacts the employees' job satisfaction, performance, and motivation. Hope supports the desires of positive outcomes and gives the feeling of being good to make the dreams come true in human life. It can be determined as a feature which awakes people to get a motivation. Motivated people unselfishly work and perform their abilities. It can be said that hope is related to the motivation and therefore Adams III, et al. underlined that it has a positive and significant relationship with job satisfaction and performance. On the other hand, hope can be defined as energy focused on the personal goals and a way or alternative ways which direct people to the target. Hope is a tool that motivates people while doing their job requirements. Several other researches also point out that hope is positively related to life satisfaction, work satisfaction and performance, and motivation to cope with stressful events. It is possible to confuse hope with optimism. Hope is described as a pathway to achieve the goals and Snyder et al. determined hope as a motivational state which has two dimensions, agency and pathways. Agency is a determination that directs the goals while the pathway is described as a plan to achieve desired goals. In addition, Rick Snyder's large scaled concept building study and research in 2000 identified three fundamental concepts and dimensions of hope to be agency, pathways, and goals by adding one more. Goals are the main desires to be attained. Under the light of this information, optimism as distinct from hope is defined as an "explanatory style" to expect good and positive results.

Optimism

Optimism can be defined as a psychological intension and expectation to hope the best possible and positive outcome which can positively influence peoples' mental and physical health. This gives individuals a chance to make their life easier and leave out of stress. Optimists distance themselves from depression and hopelessness.

Optimist 
Managers and sales representatives are much more successful than pessimist ones while playing their trade. Optimist people expect that positive situations will happen while pessimists are expecting that negative things will take place. On the other hand, optimists as opposed to pessimists also enjoy finding good things from adversity and pessimists are always ready to easily give up in face of bad and sad things in life. Researches by Hmieleski et al. demonstrated that optimism and personal wellbeing have a positive relationship in psychological capital. Similarly, again Carver et al. emphasized that optimists are able to differ in approaching "problems and challenges"; and differ in "manner and success" to deal with adversity. It has been supported by Luthans et al...That optimist has high level of job satisfaction.

\section{Resiliency}

Resiliency which is defined as a tendency to recover from adversity or depressing process, allows people to optimistically look at the overwhelming situations. Luthans et al...illustrated that resilient people can change for the better through the complexity. Resiliency has a reactional character that affects people to orient to the all kinds of situations faced in their life. Özkalp put into words this term as a complex life process for the people who include the endurance, tolerance, reactions, flexibility, and psychological pressures. Psychological resiliency is characterized as an ability for bouncing back, focusing on the goals and success. In the meantime, research by Luthans et al. supports that psychological resiliency is the coping skills of people in case of uncertainty, negative situations, and obstacles; and according to Çetin, et al . it contains in itself the other components hope, selfefficacy, and optimism. Masten put into words that resiliency has three manageable, developable components such as; asset factors that increase the level of personal resiliency, risk factors which guides to lower levels of resiliency, and influence processes. Ann Masten also highlights that resilient people are able to succeed and learn something in mischance. These resilient people can easily keep up with the changes in life. It can also be said that Resiliency can be developed and managed by other three basic components of psychological capital, self-efficacy, hope, and optimism. As a general conclusion for the components of psychological capital, each of these four basic components of positive psychological capital is "measurable, developable, entegrable" to the individuals. In order to improve and develop psychological capital and its components, people should not give up in the face of adversity and they should always resist and persevere. For this sense, psychological capital can be thought as a construct of tenacity. Last but not least, Bandura touches on the subject by emphasizing that these four positive dimensions interact in a synergy as briefly mentioned above. In such a way that, hopeful people are more resilient and motivated to deal with difficulties in their life. On the other hand, self-confident people can easily adapt and transfer their optimist thoughts and resistances. Peterson, et al.also emphasizes that because of this synergistic work of all these constructs; when one component is influenced, it is most probably that the others will also be eventually influenced. Searching for positive experiences while confirming what we do not know and accepting what we cannot know are also involved in realistic optimism. Optimism is a fact that can be managed by stress management. Although resiliency developed by focusing on the risk, asset, and organization processes, seen as a post-factum calibration, it is a "lifelong developmental journey" in reality. As Luthans et al. emphasized that it is the fact that well-managed positive psychological capital will help to establish the criteria for long-term business success and competitive advantages across the board. For this sense, organizations should focus on the positive behaviors of employees for transferring them to productivity in today's globalizing world. By the way, managers and entrepreneurs should increase employee well-being by giving a positive outlook besides their level of general and individual well-being with job satisfaction and motivation to build and develop psychological capital. On the other hand, developing success can be gained by psychological capital because it provides people an opportunity for training and improving themselves

\section{REVIEW of LITERATURE}

A large number of studies have been conducted in India and abroad covering different aspects of PSYCHOLOGICAL CAPITAL . The purpose of this Literature survey is to identify the factors that previous researchers have found to be important in combating 
occupational stress. These factors are then used in the design of the questionnaire used for data collection. Xirui Li, The Role of Psychological Capital between Occupational Stress and Job Burnout among Bank Employees in China, CHINA, Int. J. Environ. Res. Public Health 2015 examined the relationship between occupation stress and job burnout, and role of PsyCap among Chinese employees. A sex difference was observed in PsyCap combating occupational stress and job burnout. For male bank employees, levels of emotional exhaustion and personal accomplishment in both male and female bank employees were lower than in doctors female individuals in China, whereas the level of depersonalisation was higher. This study results identified PsyCap as a positive tool for reducing the negative impact of occupational stress on job burnout. Besides reducing excessive effort and commitment and increasing recognition and rewards/incentive in bank organization, management should increase PsyCap to decrease job burnout among bank employees, especially female individuals. Yang Wang, Work-family conflict and burnout among Chinese female nurses: the mediating effect of psychological capital, China medical university, BMC Public Health 2012, examine nurses which is positively related with mental tiredness and self esteem specifically among Chinese nurses. Working female (nurses) suffer problems/conflict in managing household when they focus with professional efficacy, female involvement in house had a harmful impact on professional outcome. PsyCap bring out the effects of work on household management of nurses and mediated mental tiredness and self motivation. Hence, development of psychological capital is promoted among nurses in future. $\mathbf{J}$ a $\mathbf{m} \mathbf{e} \mathbf{s} \mathbf{b}$. Av e $\mathbf{y}$, psychological capital: a positive resource for combating employee stress and turnover, new jersey, human resource management 2009 examined critical positive resource(Positive organizational behaviour)of psychological capital relates to develop future understanding regarding workplace stress. This study reflects the importance of unpredictable research and practice on how PsyCap training may be a beneficial to organizational stress management in an organization. Workplace stress cannot fully remove or eliminate from professional life. Supporting and accompanying employees effectively manage stress, however, it is objective of
HRM. Every pillar of PsyCap are open to development and is developed in short training interventions with employees. Human resource manager is providing new human resource development to use them effectively and manage their occupational stress level.

Ms.Amathul Mubeen, Maheen Fatima, Psychological Capital - A Buffer to Stress at College and Corporate, TAMIL NADU, IOSR Journal of Business and Management (IOSRJBM), 2017 examined the People with high selfefficacy believed that stresses and obstacles are challenges which must be overcome to achieve success, and instead consider them as burden. There are many ways for managing stress, such as meditation, Yoga etc. Distress destroys employees' positive attitude which lead to absenteeism, turnover, immoral, anxiety, depression, aggressiveness etc. Employee should able to recognize the marks and symptoms of stress in order to accept/adopt organizational changes. IOSR Journal of Business and Management, Psychological Capital - A Buffer to Stress at College and Corporate, Ms.Amathul Mubeen, Maheen Fatima(2006); found that Occupational happiness reflects the subjective wellbeing of individuals at the workplace, and refers to the positive and negative emotional feelings of employees towards their jobs as well as their cognitive evaluations of their jobs. Occupational health psychology and combat the harmful effect on their health is important to understand. Potential aversive reaction by an employee to a stressor, such as anxiety, frustration or physical symptoms such as stomach upset, headache etc are discussed in this paper. Another important challenge for future is to help people to come up with stress and reduce negative effects of stress which is studied and presented in this report. Department of Psychology, Howard College, University of KwaZuluNatal South Africa, Psychological capital, work engagement and organizational commitment, Janet C. Simons and Johanna H. Buitendach,(2013); People spend most of their lives in their working environments. It is becoming of such importance that managers in organizations cannot ignore the human factor in general (and PsyCap in particular) in their quest for long-term survival and excellence. These research findings will benefit all parties in the workplace and pave the way for the development of intervention 
programmes to develop the PsyCap of employees in organizations, which will then lead to them being more productive workers. Positive resource capacities of employees within context. The study adds to the existing literature on PsyCap and its relation .Universidad de San Buenaventura Colombia, International Journal of Psychological Research, vol. 10, Psychological Resources and Strategies to Cope with Stress at Work, Edna Rabenu and EyalYaniv(2017); The choice of strategies to cope with stress has differential effects on individual and organizational outcomes (e.g. well-being and performance at work). This study examined to what extent individuals differing in their positive psychological resources (optimism, hope, selfefficacy and resilience) implement different strategies to cope with stress in terms of change, acceptance, or withdrawal from a source of stress in an organizational setting. Change and acceptance tended to be aligned, and the higher the coping by change, the higher the coping by acceptance. On the other hand, there was no significant correlation between coping by withdrawal and the other modes of coping.International Journal of Academic Research in Progressive Education and Development by NurAimiNasuhaBurhanuddin, NorAniza Ahmad, SoaibAsimiran "A Systematic Review of the Psychological Capital (PsyCap) Research Development: Implementation and Gaps" (2019); examined that PsyCap as a way to flourish an individual as well as direct people to a positive outcome in work and life generally. The review also revealed a number of quantitative studies examining the relation of PsyCap to several variables and to see how it links to a positive outcome such as increase students' academic performance, academic achievement, happiness, job satisfaction and etc rather than negative outcome. Qualitative studies on PsyCap however, were limited. Minimal attention has been directed towards how the construct of PsyCap is being developed within

individual.University of Fort Hare printed South Africa Journal of Economics and Behavioral Studies, Role of Psychological Capital in Effective Management of Work-stress among Tertiary Institutions' Staff, by John K. Aderibigbe, Themba Q. Mjoli, Kolawole S. Adebisi,(2018) found that The ability of employees to effectively manage workstress is a consequence of the collective influence of self-efficacy hoe and resilience amount or levels of hope, optimism and resilience possessed and exhibited by affected individuals determine how well the person will cope and manage work-stress effectively. Gender is not strong factor to determine.

Indian institute of management calcutta, Psychological Capital as a Mediator of the Relationship between Leadership and Creative Performance Behaviors: Empirical Evidence from the Indian R\&D Sector by Vishal Gupta (2012); study identifies important leader behaviors that may impact subordinate creativity and explores the mediating role of psychological capital for the leadership-creative behavior relationship in the R\&D context. Due to its detailed and rigorous quantitative analysis, this study yields some relatively specific suggestions for managers of employees whose job involves significant creative problem solving. Having being embedded in the Indian cultural context, the results of the present work should provide important insights to anyone who is interested in studying leadership and its impact on employee creativity in the Indian $R \& D$ context. Hasan Kalyonc Üniversitesi Gaziantep, Turkey, The Effect of Psychological Capital Level of Employees Hasan Kalyonc Üniversitesi Gaziantep, Turkey, The Effect of Psychological Capital Level of Employees on Workplace Stress and Employee Turnover Intention,(2018); Employees have presented their own perception of stress levels. It is a very important limitation considering the psychological state of participants at the moment of the survey and stress causing factors in their private lives. Another limitation is employees' claims regarding their intentions to leave their jobs. Some seasonal workers may not have been honest about their thoughts since they want a permanent position, although they were informed their identities will be held confidentially .International Journal of Environmental Research and Public Health," The Mediating Role of Psychological Capital on the Association between Occupational Stress and Job Burnout", by Xirui Li , Dan Kan , LiLiu,(2015); discuses that PsyCap respectively mediated the effects of the two dimensions of occupational stress (extrinsic effort and reward) on the two dimensions of job burnout 
(emotional exhaustion and depersonalization). For female employees, PsyCap partially mediated the effects of the three dimensions of occupational stress (extrinsic effort, reward and over commitment) on the two dimensions of job burnout (emotional exhaustion and depersonalization), and also partially mediated between the one dimension of occupational stress (reward) and the one dimension of job burnout (personal accomplishment). Therefore, besides reducing excessive effort and over commitment and increasing resource rewards, bank administrators can increase PsyCap to decrease job burnout among employees, especially female individuals.

The purpose of the study was to assess the tenability of Psychological capital (positive personal) effect on gender wise teacher stressors, stress, and Affective job outcomes.

\section{RESEARCH METHODOLOGY}

OBJECTIVES OF THE STUDY: -To study the gender wise individual impact of psychological capital in combating occupational stress among teacher of educational institution in Jaipur city.

Sampling design: - The present study is a descriptive and empirical study based on primary survey of data and information, also secondary data collected from websites and magazines. For collecting the information and data, well-structured questionnaire has been prepared consisting of 14 questions psychological capital and occupational stress. The data and information has been collected from 54 respondents. The selected respondents belong to different educational institutions of Jaipur which includes Universities and schools like Jaipur National University, Neerja Modi school, American

\section{Q1) Employees feel confident in representing} their work area in meetings and management international school, kids club school, le kids preschool, Poornima University, and JECRC university etc. The questionnaire has been filled online. The study has been initiated with relevant ratios, percentages, graphs, charts etc. The applicable statistical and financial tools, techniques have also been adhered to for finalizing the conclusion of the project study. A number of journals, magazines, annual reports and websites have also been studied for finalizing the study

\section{LIMITATIONS OF THE STUDY}

In completing this research project, every effort has been made to keep the errors out, yet there are limitations of the study. A few of the limitations may be cited as under:-

1) The study is based upon primary data and as well as secondary data therefore the inferences may have been affected by the opinions of the various contributors.

2) Employees in educational institution have lot of workload. The entire questionnaire was filled at educational institution during the working hours so it is a possibility that they have filled the questionnaire in hurry.

3) The latest data, not being available the results are related to a feedback of the respondents and Responses may be influenced by the colleagues or some respondents may not disclose the truth.

\section{RESEARCH HYPOTHESIS}

\section{NULL HYPOTHESIS}

$\boldsymbol{H}_{\boldsymbol{0}}$ There is no significant influence of gender on psychological capital in combating occupational stress at educational institution in Jaipur.

$\mathbf{H}_{\mathbf{a}}$ :-There is significant influence of gender on psychological capital in combating occupational stress at educational institution in Jaipur. 


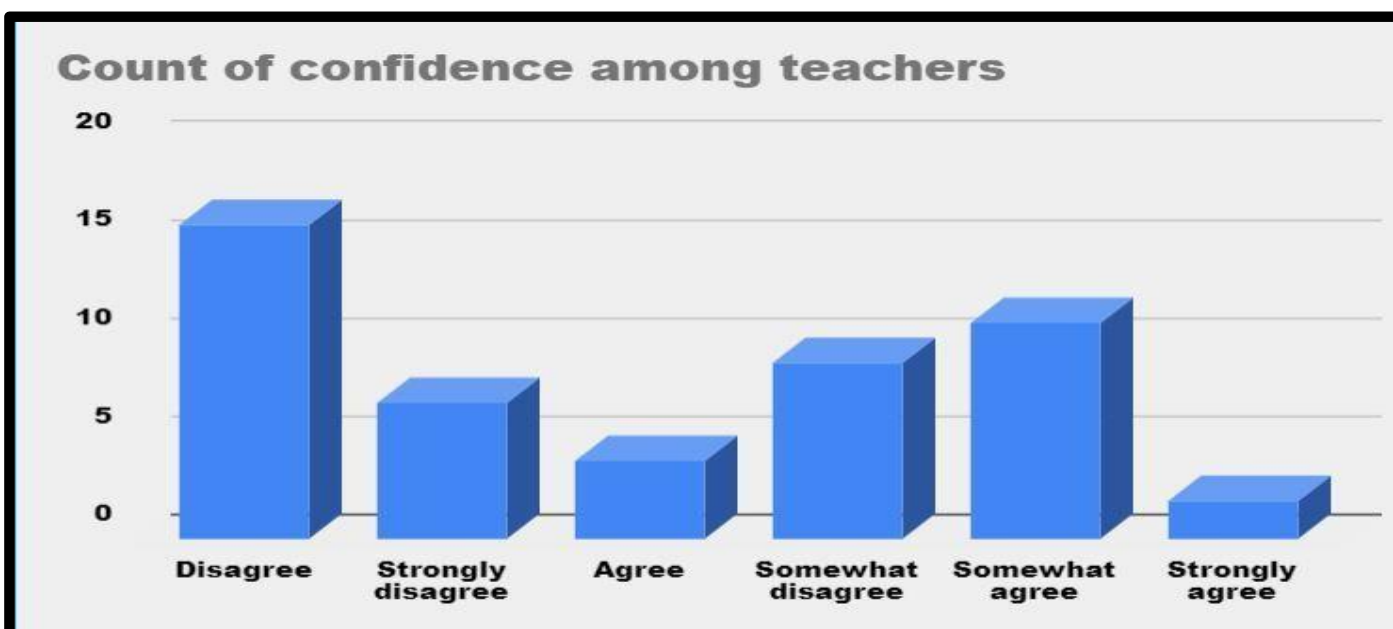

Count of $\mathbf{I}$ feel confident in representing my work area in meetings in managem...

Interpretation:- Most of the teachers/employees feels less confident in their $\mathrm{w}$

orking environment they don't feel comfort and support or feeling of self of belongingness in their organization therefore they don't feel enough in management. Whereas there were some teachers approx. $4 \%$ who strongly believe confident in their work environment.

Q2) In Past 12 Months (physical health) of employees has been decreased, improved or remain same? confidence in themselves. Around $32.7 \%$ disagreed that they are not confident in representing their work in meetings

Interpretation: - it has been found that Majority of teachers $(42 \%)$ believed that their health issues are increased due to occupational stress. Not only their mental health has been affected due to occasional stress but also their physical

\section{Count of At this time, I am meeting work goals that I have set for myself.}

$$
15
$$

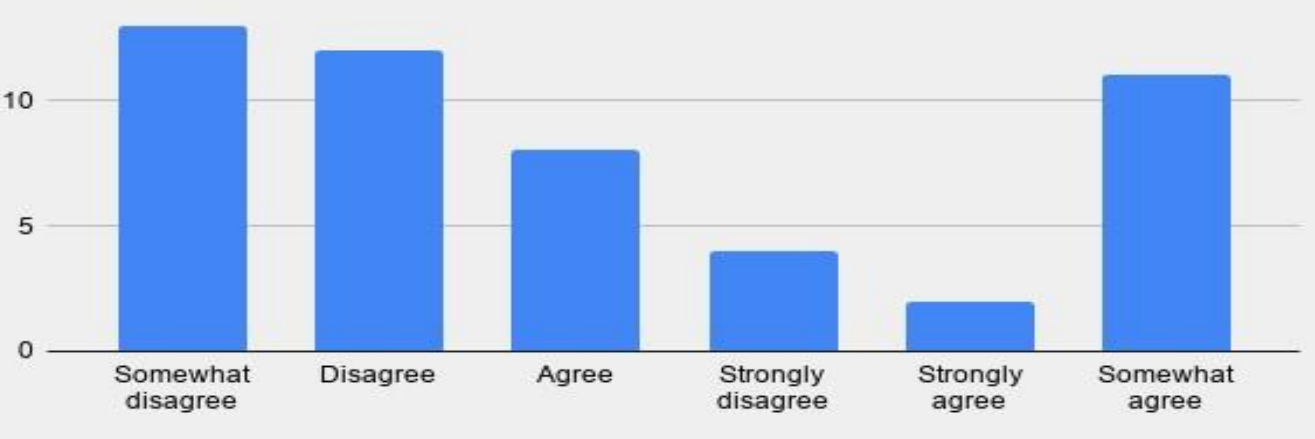

Count of At this time, I am meeting work goals that I have set for myself.

as well as emotional health has also been affected so far. Also $56 \%$ of teacher's health has remained same or improved to some extent who has maintained their body's fitness along with their routine job.
Q3) Employees are meeting work goals that they have set for themselves 
Interpretation:- It has been analyze that respondents somewhat disagree that goals are met by them, least pressure at the work place some employees were not able to set meaningful goals.

Count of In past 12 months my physical health(eg. Diet, physical health, mental strength) has

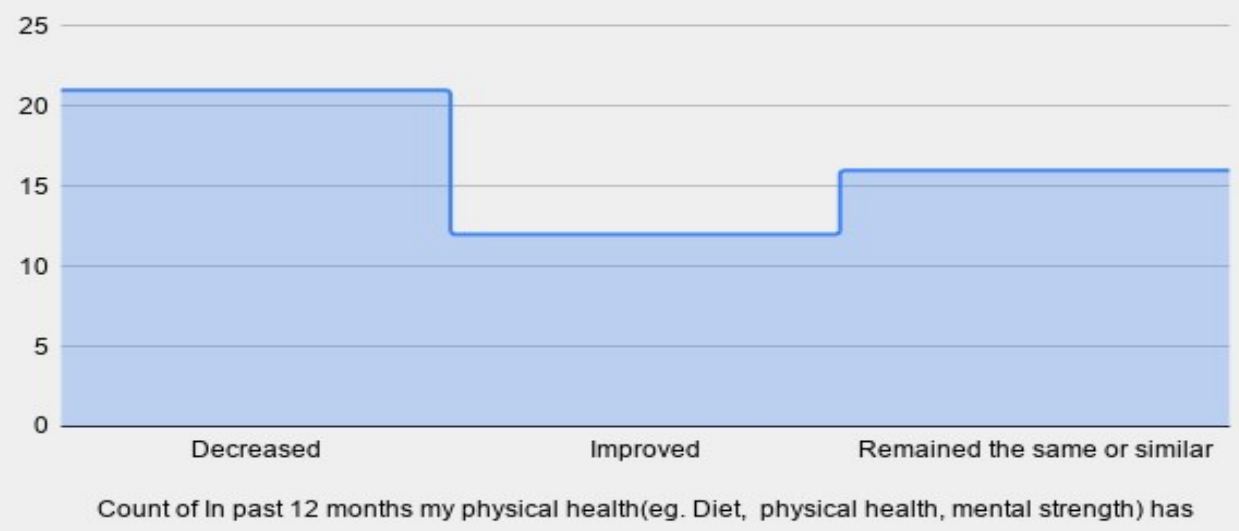

were strongly Agree meaningful goals are not set and achieve by them because of psychological

Q4) Employees are optimistic about what will happen to me in future as it pertains to work.

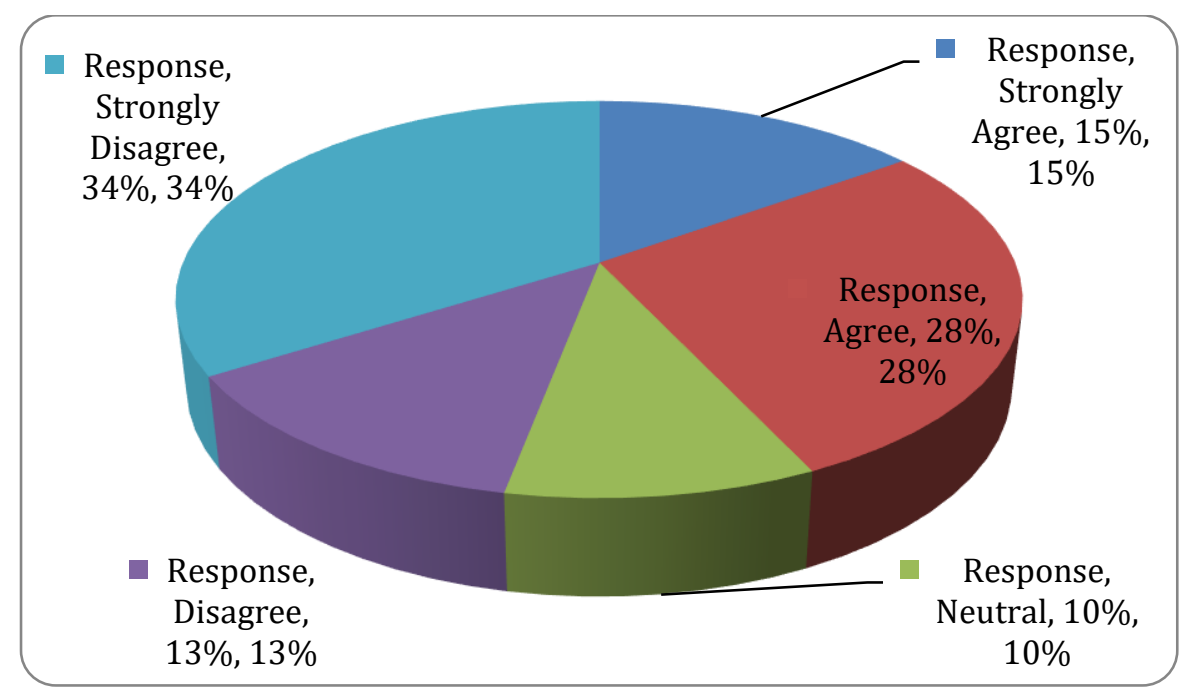

Interpretation:- It has been found from the above chart that $34 \%$ employees Strongly Disagree That what will happen to them in future as it pertains to work while 28\% employees Agree that they are optimistic about their future because they know what to do and how to do work as they have planned earlier.

Q5) Employees seldom receive adequate acknowledgement or appreciation when my work is really good. 


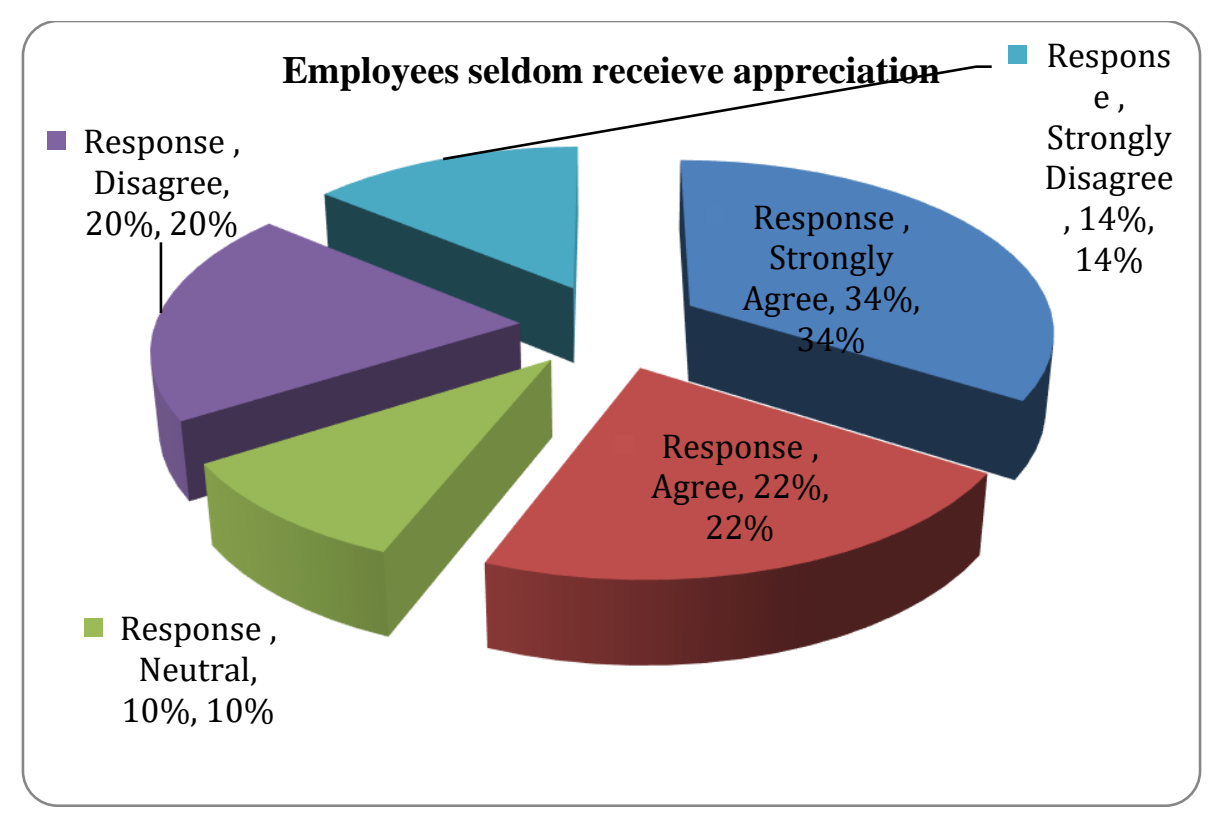

Interpretation:- $t$ has been found from the study that most employees receive appreciation in their work when their work is really good .

Q6) how would you rate the level of Job Stress?

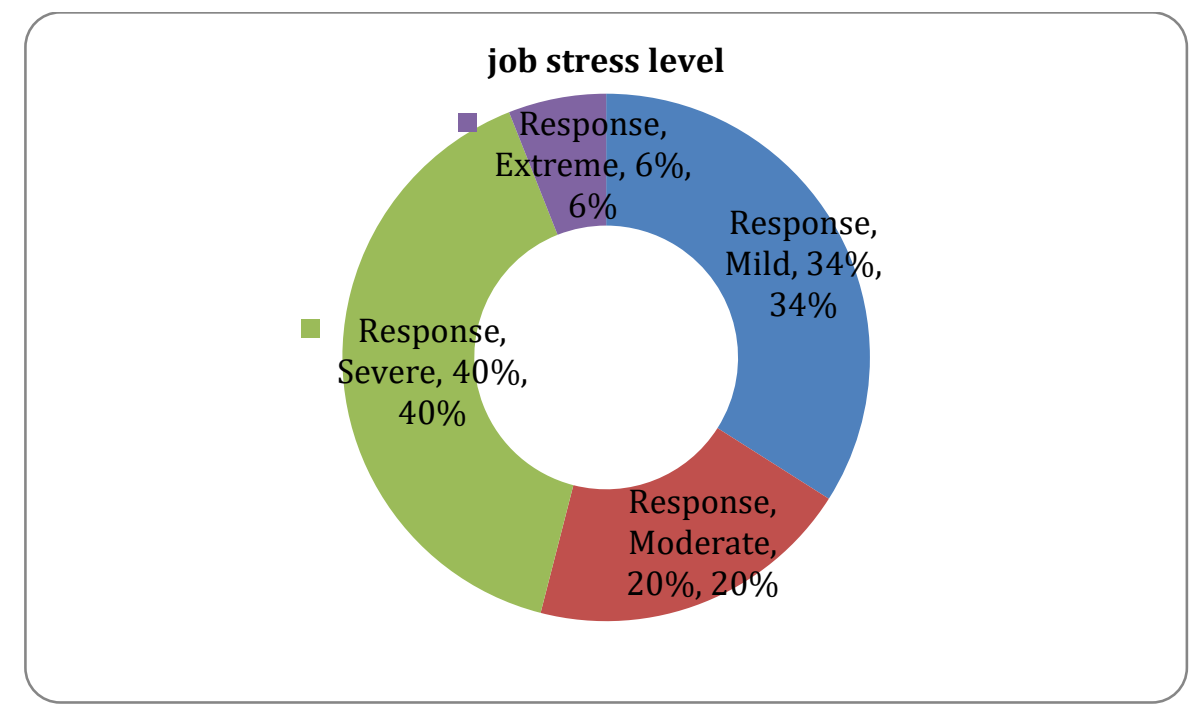

Interpretation:- It has been found that $34 \%$ of the respondent found mild level of job stress , $20 \%$ found Moderate job stress less percentage of employees have severe level of job stress because employees in academic field are working smartly and diligently

Square Test

\section{Tools Used for Interpretation}

Chai 


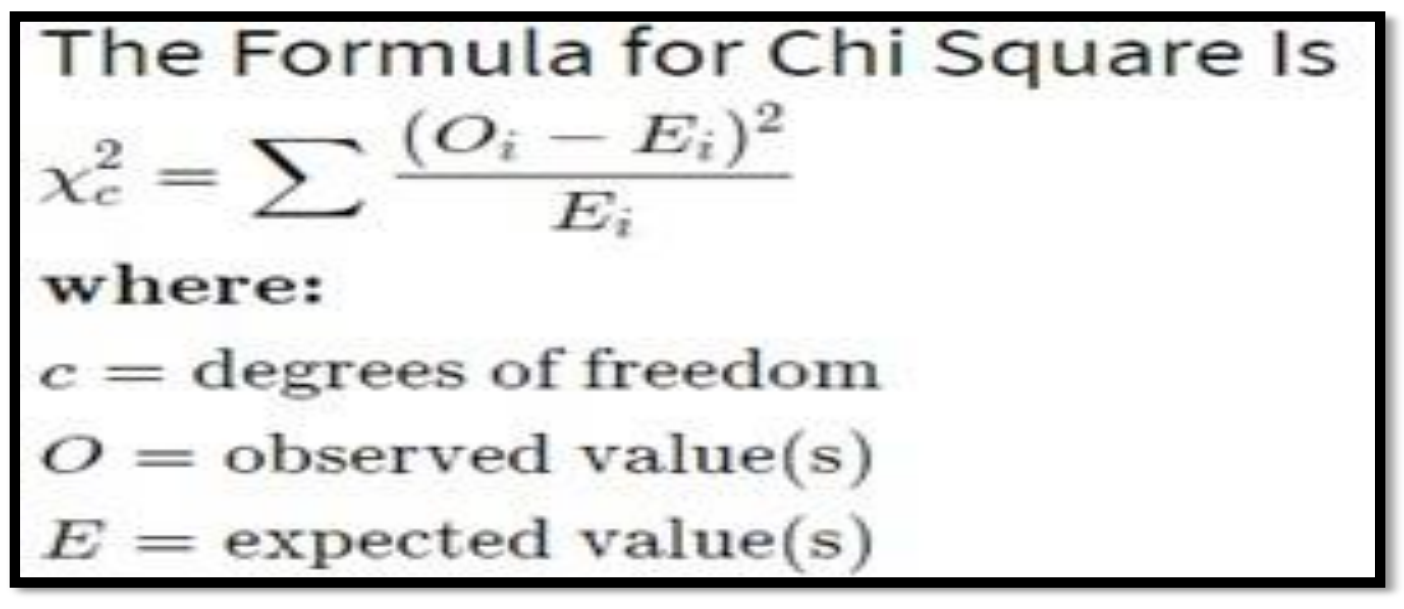

\begin{tabular}{|l|l|l|l|l|l|l|}
\hline GENDER & EXTREME & SEVERE & NULL & MODERATE & MILD & TOTAL \\
\hline MALE & 02 & 04 & 13 & 12 & 07 & 38 \\
\hline FEMALE & 01 & 02 & 05 & 03 & 01 & 12 \\
\hline TOTAL & 03 & 06 & 18 & 15 & 08 & 50 \\
\hline
\end{tabular}

\begin{tabular}{|l|l|l|l|l|l|l|}
\hline GENDER & EXTREME & SEVERE & NULL & MODERATE & MILD & TOTAL \\
\hline MALE & 6.08 & 11.4 & 13.68 & 4.56 & 2.28 & 38 \\
\hline FEMALE & 1.92 & 3.6 & 4.32 & 1.44 & 0.72 & 12 \\
\hline TOTAL & 08 & 15 & 18 & 06 & 03 & 50 \\
\hline
\end{tabular}

Expected Value 


\begin{tabular}{|c|c|c|c|c|}
\hline $\begin{array}{l}\text { Observe } \\
\text { Value }\end{array}$ & Expected value & (O-E) & $(\mathbf{O}-\mathbf{E})^{2}$ & $(\mathrm{O}-\mathrm{E})^{2} / 2$ \\
\hline 07 & 6.08 & 0.92 & 0.8464 & 0.1392 \\
\hline 01 & 1.92 & $(0.92)$ & 0.8464 & 0.4408 \\
\hline 12 & 11.4 & 0.6 & 0.36 & 0.0315 \\
\hline 03 & 3.6 & 0.6 & 0.36 & 0.1 \\
\hline 13 & 13.68 & 0.68 & 0.4624 & 0.0338 \\
\hline 05 & 4.32 & 0.68 & 0.4624 & 0.1070 \\
\hline 04 & 4.56 & 0.56 & 0.3136 & 0.0687 \\
\hline 02 & 1.44 & 0.56 & 0.3136 & 0.2177 \\
\hline 02 & 2.28 & 0.28 & 0.0784 & 0.3438 \\
\hline 01 & 0.72 & 0.28 & 0.0784 & 0.1088 \\
\hline 50 & 50 & & & 2.521 \\
\hline
\end{tabular}

X2=2.5 (approx.)

Calculation of $\mathrm{X}^{2}$

\section{Calculation of DEGREE OF}


FREEDOM (V):

\section{$\mathrm{V}=(\mathbf{R O W}-\mathbf{1}) *$ \\ (COLUMN-1)}

$\mathrm{V}=(2-1)(5-1)$

$\mathrm{V}=04$

\section{LEVEL OF}

SIGNIFIGANCE: 5\%

From Tabulated Chai Square Test, Value:-

$\mathrm{X}^{2} 0.05=9.488$

\section{CONCLUSION OF THE TEST}

Since the calculated value (2.521) is less than to the table value (9.488).

$\mathrm{X}^{2}=2.521<\mathrm{X}^{2}{ }_{0.05}=9.488$

Thus:-

Null hypothesis is accepted which means that-

There is no influence of gender on psychological capital in combating occupational stress at educational institution in Jaipur.
Suggestions and

Recommendations:

Job stress has an impact on employee job satisfaction at consolidated educational institution in Jaipur. The results show that; heavy workload in the bank has led to reduced employee satisfaction; also, role conflict in bank has reduced employee satisfaction.

Further results found that the organization does not identify areas for employee development based on feedback of performance appraisal. The degree and depth may vary from one another. Both employer and employee must understand that work should be valued and not excessive. Work should not compromise on health and family life; rather offer happiness, peace of mind, certainty, variety and flexibility.

As a general rule, actions to reduce job stress should be given top priority in the process of organizational change to improve working conditions and to avert the situation of brain drain. But even the most conscientious efforts to improve working conditions are unlikely to eliminate stress completely for all employees. The stress can be different among different employees, there by the management has to identify their problems and it will help to reduce stress. The employees are to be given enough time to complete their work which would reduce work overload. More emphasis has to be given on working condition so, that they do their work with interest. Employees can practice yoga meditation etc. helps to reduce stress and strain. Counseling can be promoted which help a person feel relief from emotional distress which develops more self- assurance, having a greater ability to make dictions and experience an increased comfort in relationship with others. The educational institution should take the initiative to identify the stress affected teachers in the school, colleges, coaching institution at frequent interval. The stress can be managed by keeping a fine balance between professional obligations and family life. Stress management program should be organized that focuses on different categories of employee's at all hierarchical level. Proper adequate steps should be taken to redesign jobs, which are taxing to employees' abilities and capacities Job oriented training programs should be introduced which improve employee's skill and their confidence to work effectively. Open channel of communication should be encouraged by 
educational institution to deal with work related stress. Stress audit should be undertaken at all levels in the organization to identify stress area improving conditions of job and alleviating job stress. Introduce 'Pranayama' (Brain Stilling and control of Vital Force) as a holistic managerial strategy to deal with occupational strategy. Proper counseling should be provided on work related and personnel problems and support from a team of welfare health and counseling staff. Educational institution should provide attractive system of reward and recognition of good work. It is advisable to all teachers to avoid unnecessary concern and competition about the colleagues' attitude. Stress management training should be conducted by educational institution with the help of professional's counselor and psychologist to cater the ever demanding job related stress. Importance of team work and group cohesiveness should be there.

Involvement of staff at various levels in decision making should be there. The educational institution should maintain the discipline among students as guided by MoA and proper regulations and rules abided at regular interval of time so that disrespect and indiscipline among student does not become a stress causing factor. Employee's grievances must be handled carefully so that they can mingle up in the working culture of the organization.

Psychiatrists should be employed so that stress audit can be conducted at all levels in the organization and stress prone areas can be identified. Organization should manage people at work differently, treating them with respect and valuing their contribution Thus, effective stress management and professional help can improve the performance of employees. Stress management programs focusing on different categories of employees' at all hierarchical level should be introduced so that employees can get a time off from their busy schedule. Jobs which are hampering employees' abilities and capacities should either be eliminated or redesigned according to employees potential Job oriented training programs should be introduced which improve employee's skill and their confidence to work effectively.

\section{Conclusion}

The study was aimed at identifying the effect of psychological capital in reducing occupational stress of teacher and shows that $72 \%$ respondents were male and $28 \%$ were female respondents. There is a highest positive involvement towards the psychological capital in male against the female.

The study concludes that the respondents were overburden with the work load in their workplaces. Work life imbalance is a big concern at educational institution in Jaipur. As the majority of respondents lives in a nuclear family are struggling to maintain balance between their work and family life. The study reveals that the respondents of schools and colleges claims that they are suffering from physical problems due to working hours and standing and excessive vocal use culture of education industry. Physical problems and health problems are increasing day by day. Behavioral problems like mood swings and reduction in motivation are seen in most of the cases.

The research also highlights that the respondents are stressful .It is also seen from the study that education sector is not playing an active role in Stress Management programmes for the teachers .This research is unique in that it integrates a broader set of antecedent variables including gender and work characteristics. A better understanding of the gender wise and work factors that lead to stress should subsequently help employees understand a greater proportion of the variance of employee's satisfaction, performance and turnover, which help them better in dealing with it. The problem of stress is inevitable and unavoidable in the teaching sector. A majority of the employees face severe stress- related ailments and a lot of psychological problems. Hence, the management must take several initiatives in helping their employees to overcome its disastrous effect. Since stress in teaching sector is mostly due to excess of work pressure and work life imbalance the organization should support and encourage taking up roles that help them to balance work and family.

\section{References}

Arulrajah, A.A. and Opatha, H.H.D.N.P. (2016), Analytical and Theoretical Perspectives on Green Human Resource Management: A Simplified Underpinning, International Business Research, Vol.9, No.12, pp. 153-164. 
Aswathappa, K. (2017), Human Resource Management: Text and Cases, New Delhi: Tata McGraw-Hill Publishing Company Ltd.

Hitt, M.A., Middlemist, R.D., and Mathis, R.L. (1979), Effective Management, New York: West Publishing Company.

Holland, P., Sheehan, C., Donohue., Pyman, A., and Allen, B. (2012), Contemporary Issues and Challenges in HRM, 2nd edi, Victoria: TILDE UNIVERSITY PRESS.

Jackson, S.E. and Schuler, R.S. (2003), Managing Human Resources, 8th ed, Mason, OH: SOUTH-WESTERN CENGAGE Learning.

Jackson, S.E., Schuler, R.S., and Werner, S. (2012), Managing Human Resources, 11th ed, Mason, OH: SOUTH-WESTERN CENGAGE Learning.

Noe, R.A., Hollenbeck, J.R., Gerhart, B., and Wright, P.M. (2007), Human Resource Management, New Delhi: Tata McGraw-Hill Publishing Company (Indian Print).

Opatha, H.H.D.N.P. (1994), Employee Grievance Settlement Procedure: A Case Study of Two Corporations, Management Review, Faculty of Management Studies and Commerce, University of Sri Jayewardenepura, Sri Lanka, Vol. 1, No.2, pp.53-60. 